\title{
Synthesis and In Vitro Antimicrobial Evaluation of Photoactive Multi-Block Chalcone Conjugate Phthalimide and 1,8-Naphthalimide Novolacs
}

\author{
Periyan Durairaju ${ }^{1,2, *}$, Chinnasamy Umarani ${ }^{2}$, Govindasami Periyasami ${ }^{3, * \mathbb{D}}$, \\ Perumberkandigai Adikesavan Vivekanand ${ }^{4}$ and Mostafizur Rahaman ${ }^{3}$ \\ 1 Department of Chemistry, Thiruvalluvar Government Arts College, Namakkal 637401, India \\ 2 Department of Chemistry, Government Arts College (Autonomous), Salem 636007, India; \\ sachuutay@gmail.com \\ 3 Department of Chemistry, College of Science, King Saud University, Riyadh 11451, Saudi Arabia \\ mrahaman@ksu.edu.sa \\ 4 Department of Chemistry, Saveetha Engineering College, Chennai 602105, India; pavivek@rediffmail.com \\ * Correspondence: rajanorgyeschem@gmail.com (P.D.); pkandhan@ksu.edu.sa (G.P.)
}

check for

updates

Citation: Durairaju, P.; Umarani, C.; Periyasami, G.; Vivekanand, P.A.;

Rahaman, M. Synthesis and In Vitro Antimicrobial Evaluation of

Photoactive Multi-Block Chalcone

Conjugate Phthalimide and

1,8-Naphthalimide Novolacs.

Polymers 2021, 13, 1859. https://

doi.org/10.3390/polym13111859

Academic Editor: Ana

María Díez-Pascual

Received: 19 April 2021

Accepted: 24 May 2021

Published: 3 June 2021

Publisher's Note: MDPI stays neutral with regard to jurisdictional claims in published maps and institutional affiliations.

Copyright: (C) 2021 by the authors. Licensee MDPI, Basel, Switzerland This article is an open access article distributed under the terms and conditions of the Creative Commons Attribution (CC BY) license (https:// creativecommons.org/licenses/by/ $4.0 /)$

\begin{abstract}
Herein we report new multiblock chalcone conjugate phthalimide and naphthalimide functionalized copolymers with a topologically novel architecture synthesis using nucleophilic substitution and polycondensation methodology. The structures of the synthesized novolacs were elucidated on the basis of their spectroscopic analysis including FTIR, ${ }^{1} \mathrm{H}$ NMR, and ${ }^{13} \mathrm{C}$ NMR spectroscopy. Further, the number-average and weight-average molecular weights of the novolac polymers were determined by gel permeation chromatography (GPC). We examined the solubility of the synthesized polymers in various organic solvents including $\mathrm{CHCl}_{3}, \mathrm{CH}_{3} \mathrm{CN}, \mathrm{THF}, \mathrm{H}_{2} \mathrm{O}, \mathrm{CH}_{3} \mathrm{OH}$, DMSO, and DMF and found they are insoluble in both methanol and water. The novolac polymers were evaluated for their photophysical properties and microbial activities. The investigation of the antimicrobial activities of these polymers reveals significant antimicrobial activity against the pathogens E. coli, S. aureus, C. albicans, and A. niger.
\end{abstract}

Keywords: N-substituted phthalimide; fluorescent naphthalimide; chalcone spacer; phenolformaldehyde resins; antimicrobial activity

\section{Introduction}

Polymeric fluorescent compounds are an attractive research area for researchers in both academia and industries including textiles, food, cosmetics, and biomedicines. Among the various available fluorescent materials in the literature, polymeric compounds containing phthalimides and 1,8-naphthalimide analogs exhibit a wide range of applications [1-3]. The structural feature of -CO-N(R)-CO- and the imide ring functionality in phthalimides are responsible for the bioactivity and pharmaceutical properties of the analogs. Interestingly, due to their hydrophobic and neutral nature, phthalimides can cross biological membranes in vivo [4]. Moreover, they exhibit antioxidant and anti-inflammatory properties [5,6], have antimicrobial potential [7], and possess anthelmintic activity [8]. In 2012, Basaric et al. found that phthalimides can produce tumor necrosis factor (TNF $\alpha$ ) to suppress tumor cell proliferation [9]. Furthermore, phthalimide polymers are widely used in biomedical and biological fields with a variety of properties including antimalarial, anti-influenza, anticancer, anti-inflammatory, and antifungal activities, apoptotic-inducing properties, and in applications such as protein sensors, n-type organic semiconductors, and electroluminescence [10-14].

Similarly, naphthalimide and its derivatives are a unique class of fused naphthalene compounds in which a chalcone is fused to a naphthalimide moiety. Naphthalimide derivatives possess a broad range of biological activities such as antiviral [15], antioxidant [16], 
antitumor [17], and antimicrobial activities [18]. In 2017, Al-Azzawi and Faiq reported a variety of new phenolic resins bearing 1,8-naphthalimide pendent groups for various applications [19]. They also act as blue-light-emitting materials because of their highly efficient fluorescence and photoluminescence, thermal and oxidative stability, and emission of polarized blue light [20]. Hence, during recent decades, remarkable advances have been made in the production of naphthalimide polymeric derivatives. For instance, allyloxyand alkoxy-substituted 1,8-naphthalimide copolymeric materials emit bright blue fluorescence and can be used as brightening agents for polymers [21]. In 2020, Hudson et al. [22] reported that 1,8-naphthalimide-based deep-red acrylic polymers could be applied as ratiometric temperature sensors. Very recently, a ratiometric fluorescent nanoprobe based on naphthalimidefunctionalized carbon dots was developed for HeLa cellline studies [23]. Motivated by their notable fluorescent and biological characteristics, we were interested in investigating phthalamide- and naphthalimide- based fluorescent novolac analogs. In this work, we propose the synthesis and characterization of a new type of highly structured chalcone conjugated fluorescent resins bearing naphthalimide and phthalimide pendants on the novolac backbone. Further, the synthesized fluorescence novolac resins exhibited in vitro inhibitory activity against highly threatening pathogens.

\section{Materials and Methods}

All required chemicals were purchased from Sigma (Bangalore, Karnataka, India), Merck (Mumbai, Maharashtra, India), and Alfa Aesar (Melbourne, Australia). ${ }^{1} \mathrm{H}$ and ${ }^{13} \mathrm{C}$ NMR spectra were recorded on a Bruker $400 \mathrm{MHz}$ instrument (SAIF-IITM, Chennai, India). UV-Vis absorption spectra were recorded on a Perkin Elmer LAMBDA 950 spectrophotometer (SAIF-IITM, Chennai, India), and fluorescence measurements were performed on a Spectra Max Fluorolog-3 instrument (SAIF-IITM, Chennai, India) at room temperature. Silica gel (60-230 mesh) (LOBA Chemie, India) was employed for routine column chromatography separations. Thin layer chromatography (TLC) was performed on precoated $(0.25 \mathrm{~mm})$ silica gel F 254 plates (E. Merck, Germany); naphthalimide derivatives were detected using a $254 \mathrm{~nm}$ UV lamp. Melting points were recorded on MEL-TEMP Electrothermal melting point apparatus (Electrothermal, Germany) and were uncorrected.

\subsection{General Procedure for the Synthesis of Isoindoline-1,3-Diones 3 and 7}

Isoindoline-1,3-diones 3 and 7 were prepared following a literature procedure [24]. Briefly, 4-aminoacetophenone was reacted with the appropriate acid anhydride in glacial acetic acid $(50 \mathrm{~mL})$. The reaction mixture was heated to boiling temperature $\left(118^{\circ} \mathrm{C}\right)$ for $16 \mathrm{~h}$ with constant stirring and monitored by TLC to determine the completion of the reaction. Then, the reaction mixture was allowed to cool to room temperature, and ice-cold water was added. The resulting solid was filtered off and dried, and the crude product was purified by recrystallization from a hot $\mathrm{EtOH}: \mathrm{CHCl}_{3}(1: 1)$ mixture.

\subsection{General Procedure for the Condensation Reaction to Synthesize $4 a-c$ and $8 a-d$}

An equimolar mixture of the appropriate aromatic aldehyde and isoindoline-1,3-dione 3 or 7 was stirred with $10-20 \mathrm{~mL}$ of ethanol, and $10 \mathrm{~mL}$ of a $40 \%$ aqueous $\mathrm{KOH}$ solution was added at room temperature. The reaction mixture was stirred overnight, and the completion of the reaction was determined by TLC. The reaction mixture was poured into ice-cold water and acidified with dilute $\mathrm{HCl}$ to precipitate the crude product, which was then recrystallized with hot ethanol.

\subsection{General Procedure for the Synthesis of Compounds $\mathbf{5} \boldsymbol{a}-\boldsymbol{c}$ and $\mathbf{9 a}-\boldsymbol{d}$}

An equimolar mixture of chalcone $4 \mathbf{a}$ and formaldehyde was placed in a $250 \mathrm{~mL}$ round bottom flask fitted with a mechanical stirrer and a condenser to allow melting at $60{ }^{\circ} \mathrm{C}$ with constant stirring under $\mathrm{N}_{2}$ atmosphere. Then, $5 \mathrm{~mL}$ of TEA was added dropwise, and the reaction mixture was allowed to reflux for a further 6-7 h under $\mathrm{N}_{2}$ atmosphere. After TLC indicated consumption of the reactants, the reaction mixture was allowed to cool down. 
Then, the excess of TEA was removed by washing with diethylether $(3 \times 15 \mathrm{~mL})$, and the solid mass was poured into hot ethanol and dried overnight under vacuum in a hot oven at $50{ }^{\circ} \mathrm{C}$.

\subsection{Determination of Molecular Weight}

The most significant parameter in polymer characterization is the determination of molecular weight. In the current study, we found the molecular weights of the novalac polymers using gas permutation chromatography (GPC), a reliable and systematic technique. The number-average molecular weights $(\mathrm{Mn})$ and the weight-average molecular weights $(\mathrm{Mw})$ of the polymer samples were determined using a Waters 510 HPLC pump (Waters, Hayward, NJ, USA) equipped with a Waters 410 Differential Refractometer instrument (Waters, Hayward, NJ, USA) at an operating wavelength $(\lambda)$ of $930 \mathrm{~nm}$. Gel permeation chromatography (GPC) consisted of three sets of Waters Styragel columns, viz., HR1, HR2, and HR3, having a size of $7.8 \mathrm{~mm}$ in diameter and $300 \mathrm{~mm}$ in length. Initially, the instrument calibration techniques were done according to the standard method with poly(styrene) standard and the experiment was carried out at $40 \pm 1{ }^{\circ} \mathrm{C}$ using HPLC grade acetonitrile $\left(\mathrm{CH}_{3} \mathrm{CN}\right)$ as the mobile phase at a flow rate of $1.0 \mathrm{~mL} / \mathrm{min}$.

\subsection{Spectrophotometric Studies}

\subsubsection{FourierTransform Infrared Spectroscopy}

The Fouriertransform infrared spectroscopy (FTIR, Shimadzu, Japan) spectra were recorded in a Shimadzu FTIR 8400 spectrophotometer instrument using a KBr disc back as a reference. Spectra were acquired between 4000 and $400 \mathrm{~cm}^{-1}$, accumulating up to 45 spectra with a resolution of $2 \mathrm{~cm}^{-1}$.

\subsubsection{Absorption and Emission Spectral Studies}

The UV-Vis double beam UVD-3500 Labomed Inc. (Los Angeles, CA, USA) instrument was used to record absorption spectra at room temperature, and the emission spectra were recorded in a PerkinElmer Luminescence PE 45 instrument. Spectroscopic grade acetonitrile was used as a solvent to record the emission spectra, and the concentration of $1 \times 10^{-6} \mathrm{M}$ synthesized novolac solutions was prepared by sonication for $10-15 \mathrm{~min}$ as it has poor solubility. The slit width was $5 \mathrm{~nm}$ at input and output pathways and the path length of the cuvette was $10 \mathrm{~mm}$.

\subsection{Antimicrobial Studies}

Antimicrobial activities of the synthesized phthalimide and naphthalimide novolacs were used to screen primary biological studies. All the synthesized compounds $\mathbf{5 a - c}$ and 9a-d were subjected to antimicrobial activity against common pathogens such as Gramnegative bacteria (Escherichia coli MTCC 25922), Gram-positive bacteria (Staphylococcus aureus MTCC 25923), pathogenic yeast (Candida albicans MTCC 282), and a fungus (Aspergillus niger MTCC 227), which are usually found in vegetables and fruits. The agar diffusion method was used for the determination of antimicrobial activities against the above-mentioned microorganisms by standard methodology [25]. All the cultures were maintained in the standard laboratory conditions. Wells were made with a cork borer in the solid agar and loaded with 50,75, and $100 \mathrm{mg} / \mathrm{mL}$ of the novolacs dissolved in DMSO with tetracycline and carbendazim as control for E. coli, S. aureus, C. albicans, and A. niger, respectively. Petri dishes were incubated at $35^{\circ} \mathrm{C}$ for $24 \mathrm{~h}$ and the resulting inhibition zone diameter was measured in millimeters.

\section{Results and Discussion}

\subsection{Synthesis}

The synthesis of phthalimide analogs $\mathbf{5 a - c}$ and 1,8-naphthalimide analogs $\mathbf{9 a -} \mathbf{a}$ was performed as depicted in Schemes 1 and 2, starting from key materials 1 and 2 and 1 and 6, respectively. Initially, 2-(4-acetylphenyl)isoindoline-1,3-dione (3) and 2-(4-acetylphenyl)- 
5-substituted-1H-benzo[de]isoquinoline-1,3(2H)-dione (7) were synthesized according to a literature procedure [24] by the reaction of the corresponding aromatic anhydride with 4 -aminoacetophenone in acetic acid under reflux. In the second step, the required chalcone was obtained by aldol condensation and subsequent dehydration of 1,3-diones 3 and 7 with various substituted aromatic aldehydes in ethanolic solution in $\mathrm{KOH}$ medium. The obtained crude products were dissolved with hot ethanol and recrystallized to produce chalcones $\mathbf{4 a - c}$ and $\mathbf{8 a}-\mathbf{d}$. These chalcones underwent polymerization by the reaction with formaldehyde in a ratio of 1:8 in the presence of triethylamine (TEA) in ethanolic solution at $65^{\circ} \mathrm{C}$ under $\mathrm{N}_{2}$ atmosphere, producing phenolic-formaldehyde resins $5 \mathbf{a}-\mathbf{c}$ and $\mathbf{9 a}-\mathbf{d}$ in $50-56 \%$ yields.

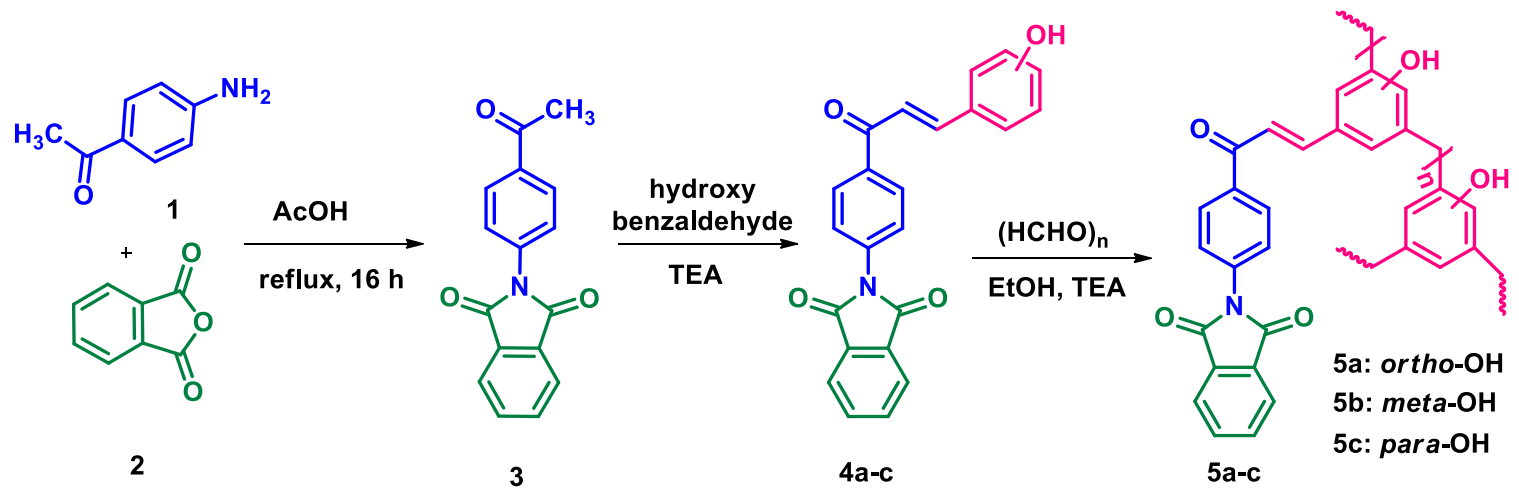

Scheme 1. Synthesis of N-substituted phthalimide phenol analogs 5a-c.

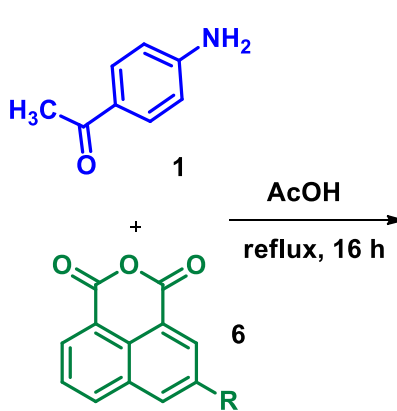

$R: 6 a=H, 6 b=\mathrm{NO}_{2}$

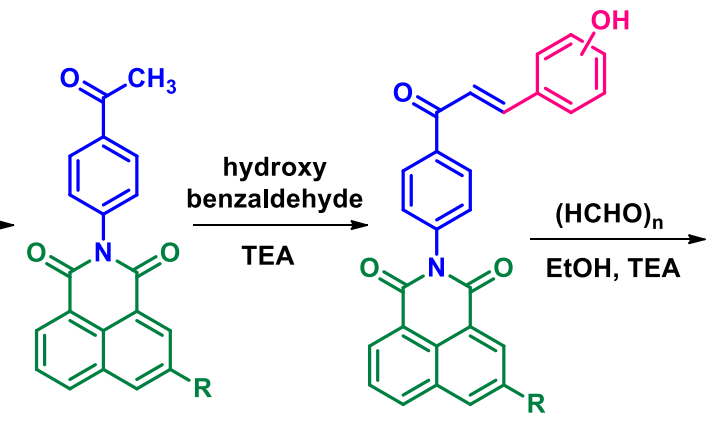

8a-d

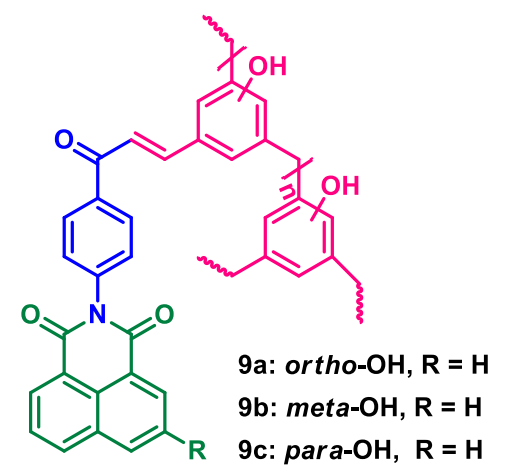

9a-d 9d: $m e t a-\mathrm{OH}, \mathrm{R}=\mathrm{NO}_{2}$

Scheme 2. Synthesis of N-substituted naphthalimide phenol analogs $\mathbf{9 a - d}$.

The structures of the newly synthesized compounds were confirmed by spectroscopic analysis. Thus, the IR spectra of $\mathbf{5 a - c}$ and $\mathbf{9 a}-\mathbf{d}$ show two strong absorption peaks between 1777 and $1660 \mathrm{~cm}^{-1}$, which revealed the presence of two carbonyl groups. The absorption peak at $1402 \mathrm{~cm}^{-1}$ (imide), together with the obvious bands around $2920 \mathrm{~cm}^{-1}$, are attributed to the amide group, which further supports the proposed structures. A representative FTIR spectrum of phthalimide pendent novolac $\mathbf{5 a}$ is shown in Figure 1. The remarkable signatures around $1790 \mathrm{~cm}^{-1}$ and $1769 \mathrm{~cm}^{-1}$ denote the asymmetrical and symmetrical stretching frequencies of imide carbonyl groups, respectively. The intense band of chalcone carbonyl carbon symmetrical stretching absorption appeared at $1727 \mathrm{~cm}^{-1}$. An absorption band that appeared around $1306 \mathrm{~cm}^{-1}$ corresponds to $\mathrm{C}-\mathrm{N}$ stretching and the sharp absorption bands that appeared around 1012 and $771 \mathrm{~cm}^{-1}$ are due to imide ring deformation. The aromatic $\mathrm{C}-\mathrm{H}$ stretching frequency has been observed at $3071 \mathrm{~cm}^{-1}$ and the absorption at $3460 \mathrm{~cm}^{-1}$ represents the presence of a phenolic $\mathrm{OH}$ group in the novolac polymer. 


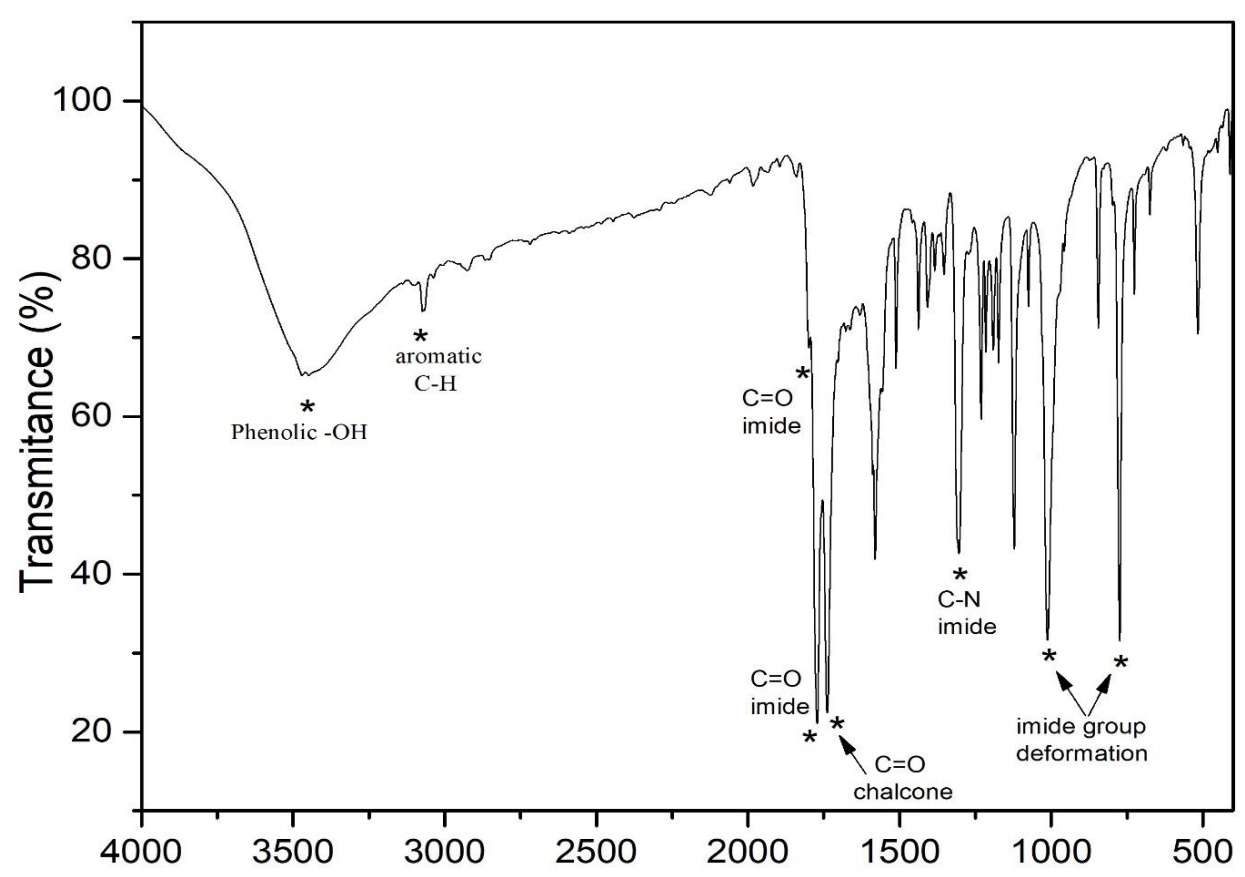

Figure 1. FTIR spectrum of phthalimide pendent novolac $5 \mathbf{a}$.

All the newly synthesized compounds structures were determined based on the standard literature procedure [26,27]. As a representative example, the ${ }^{1} \mathrm{H}$ NMR spectrum of compound 5a shows a characteristic singlet at $\delta 5.46 \mathrm{ppm}$, which is due to the presence of phenolic $\mathrm{OH}$ and a distorted doublet at $\delta 3.19$ ppm corresponding to the newly generated methylene group between the phenolic rings. The aromatic protons are observed between $\delta$ 7.19 and $8.22 \mathrm{ppm}$ (Figure 2). The ${ }^{13} \mathrm{C}$ NMR of compound 5a shows a characteristic peak at $\delta 29.71 \mathrm{ppm}$ that can be assigned to methylene carbons. The downfield peaks at 158.30 and 186.20 ppm confirm the presence of 1,3-diketonyl and $\alpha, \beta$-unsaturated carbonyl carbons in compound $\mathbf{5 a}$, respectively. The structures of the synthesized compounds $\mathbf{5 a - c}$ and 9a-d are presented in Table 1, and complete NMR data can be found in the supplementary materials (S1).

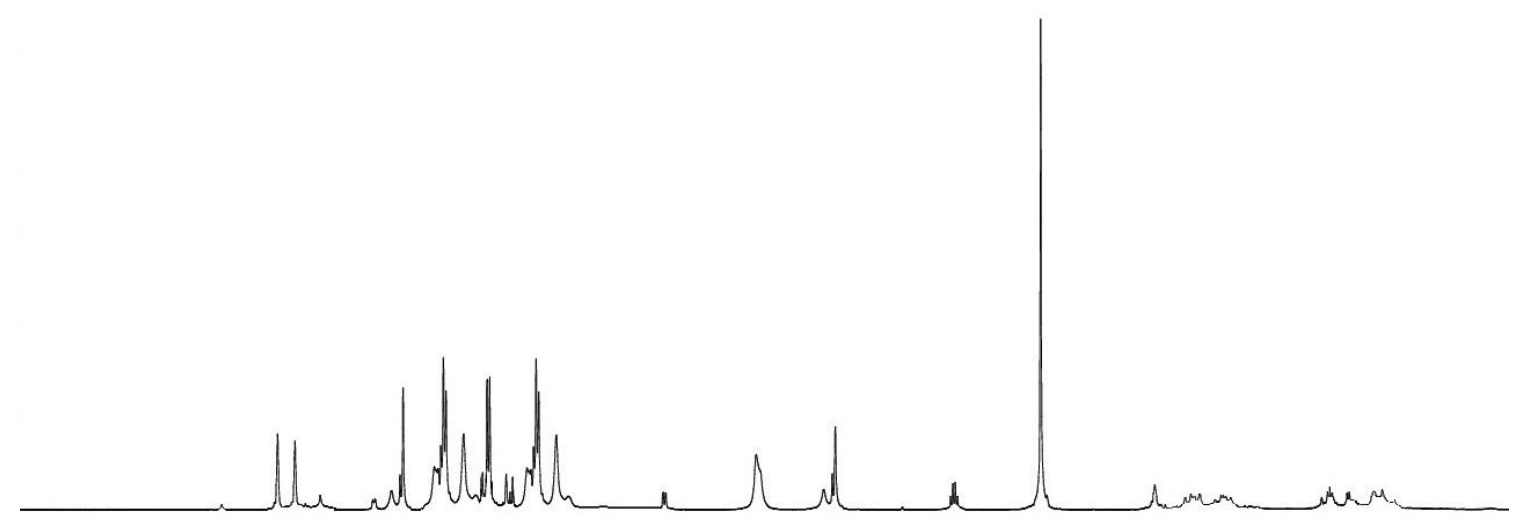

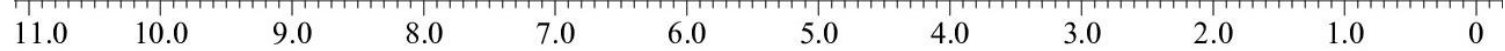

Figure 2. ${ }^{1} \mathrm{H}$ NMR spectrum of phthalimide pendent novolac 5 a. 
Table 1. Phthalimide- and naphthalimide-substituted phenol-formaldehyde polymeric resins $5 \mathbf{a}-\mathbf{c}$ and $\mathbf{9 a - d}$.

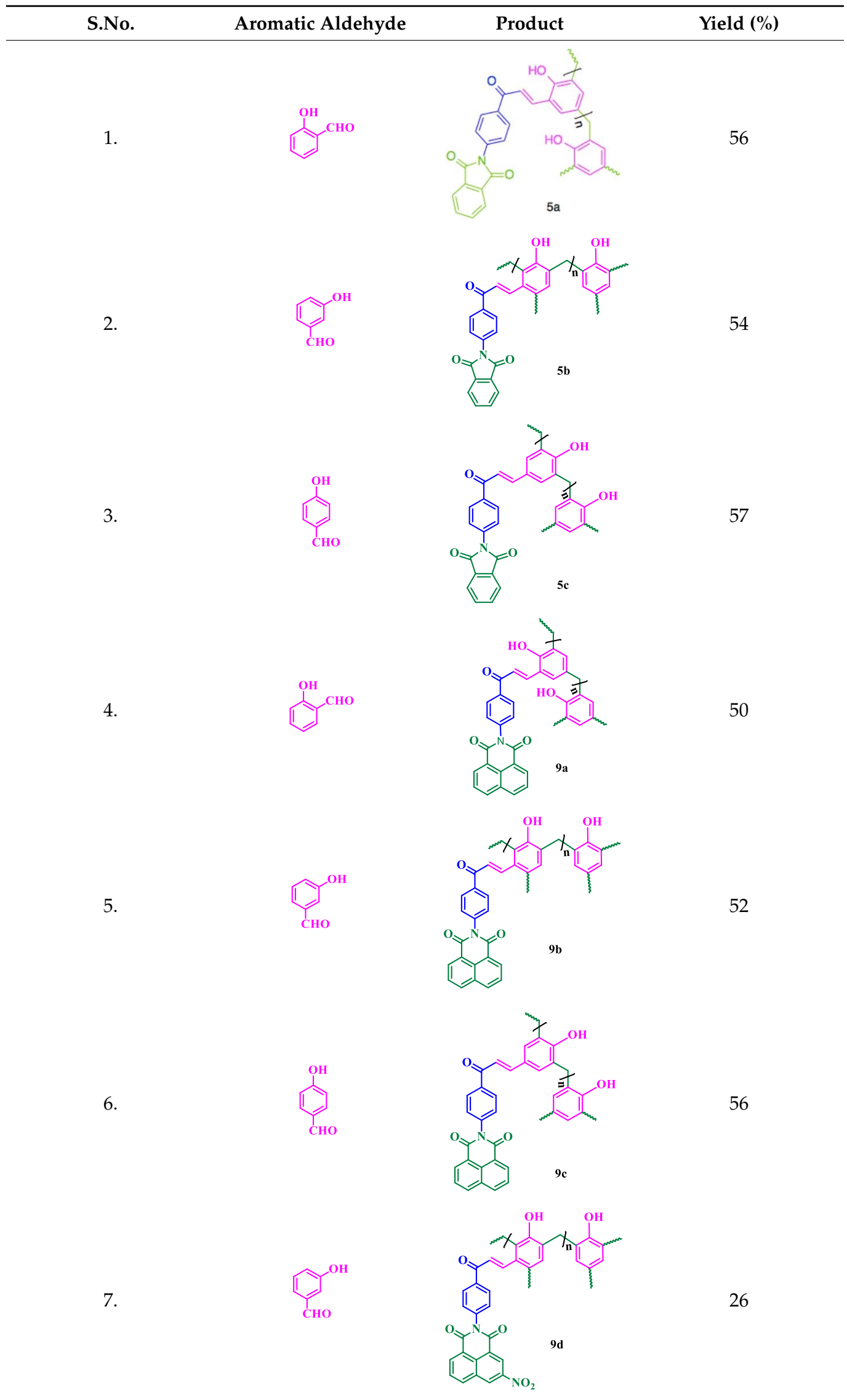




\subsection{Average Molecular Weight Analysis}

The average molecular weights $\left(M_{n}\right.$ and $\left.M_{w}\right)$ and polydispersity index $\left(Đ=M_{w} / M_{n}\right)$ of the synthesized polymers were calculated and the results are presented in Table 2 . The chromatogram of novolac $\mathbf{5 a}$ is presented in Figure 3.

Table 2. Molecular weight $\mathrm{M}_{\mathrm{n}}, \mathrm{M}_{\mathrm{w}}$, and $Đ$ of the synthesis novolac polymers $\mathbf{5 a - c}$ and $\mathbf{9 a}-\mathbf{d}$. (Results are expressed as rounded to the third significant number).

\begin{tabular}{cccc}
\hline \multirow{2}{*}{ Polymer } & \multicolumn{3}{c}{ Molecular Weight } \\
\cline { 2 - 4 } & $\mathbf{M}_{\mathbf{n}}$ & $\mathbf{M}_{\mathbf{w}}$ & $\mathbf{D}$ \\
\hline $\mathbf{5 a}$ & 16,700 & 47,200 & 2.8 \\
$\mathbf{5 b}$ & 15,169 & 52,100 & 3.4 \\
$\mathbf{5 c}$ & 15,900 & 46,500 & 2.9 \\
$\mathbf{9 a}$ & 12,100 & 53,160 & 4.4 \\
$\mathbf{9 b}$ & 14,300 & 60,300 & 4.2 \\
$\mathbf{9 c}$ & 18,600 & 50,200 & 2.7 \\
$\mathbf{9 d}$ & 9500 & 18,300 & 1.9 \\
\hline
\end{tabular}

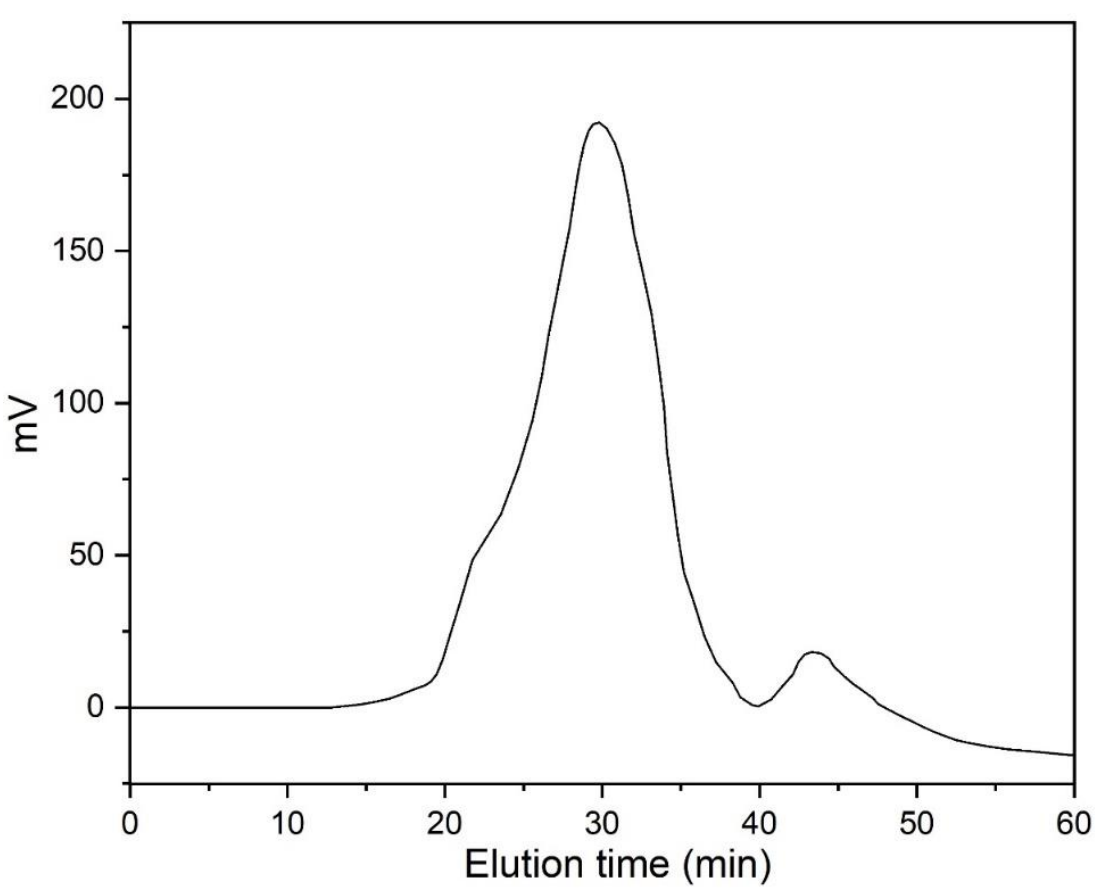

Figure 3. Molecular weight distribution chromatogram of novolac 5a from GPC.

The average molecular weight of phthalimide novolacs5a-c $\left(M_{n}=15,169-16,734\right.$, $\mathrm{M}_{\mathrm{W}}=46,512-52,110$, and $Đ=2.82-3.43$ ) was found to be lower than 1,8-naphthalimide novolacs 9a-d $\left(\mathrm{M}_{\mathrm{n}}=12,056-18,599, \mathrm{M}_{\mathrm{w}}=50,218-60,327\right.$, and $\left.Đ=2.70-4.41\right)$. The obtained high $Đ$ values $(\boxplus>3.00)$ of the synthesized polymers are due to fragmentation and recombination of the monomers. Further, we attribute the high $Đ$ values of the polymers to their branched structures. In addition, all other polymers have $Đ$ values $>2.00(Đ=2.70$, 2.82 , and 2.91), which indicates the presence of a hyper-branching chain in the synthesized polymers. The naphthalimide analog $9 d$ showed the lowest $Đ$ value $\left(M_{n}=9514\right.$, $\mathrm{M}_{\mathrm{W}}=18,326$, and $\left.Đ=1.92\right)$ compared to the other analogs due to the substituted electronwithdrawing nitro group in the naphthalimide ring.

\subsection{Absorbance Spectra}

The UV-visible absorption spectra of naphthalimide analogs $\mathbf{9 a - d}$ recorded in acetonitrile are shown in Figure 4a. It is obvious that the photochemical properties of the 
1,8-naphthalimide core are influenced by the substituents present in the aromatic ring [28]. All the synthesized naphthalimide derivatives were UV active, with maximum absorption wavelengths ( ${ }^{\mathrm{abs}} \lambda_{\max }$ ) in the region $336-343 \mathrm{~nm}$, and the acetonitrile solutions were colorless to the naked eye. The observed blue shift of the absorbance of 1,8-naphthalimide is due to the presence of the chalcone. In general, the $n-\pi^{*}$ transition of chalcone compounds is stronger than their $\pi-\pi^{*}$ transition owing to the presence of an extended $\pi$-conjugation system in the structure. Xiao et al. [29] reported the synthesis and characterization of 4-(2-methoxyethoxy)-N-butyl-1,8-naphthalimide (MEBN), and they found that MEBN had a abs $\lambda_{\max }$ value at $355 \mathrm{~nm}$, whereas that of 4-methoxy-N-butyl-1,8-naphthalimide was $350 \mathrm{~nm}$, which was attributed to the presence of the more strongly electron-donating methoxy-ethoxy group compared to the methoxy group. The fluorescent molecules based on 1,8-naphthalimide thio and amino derivatives exhibit maximum excitation wavelengths ranging between 390 and $398 \mathrm{~nm}$, which agrees well with literature reports [30].
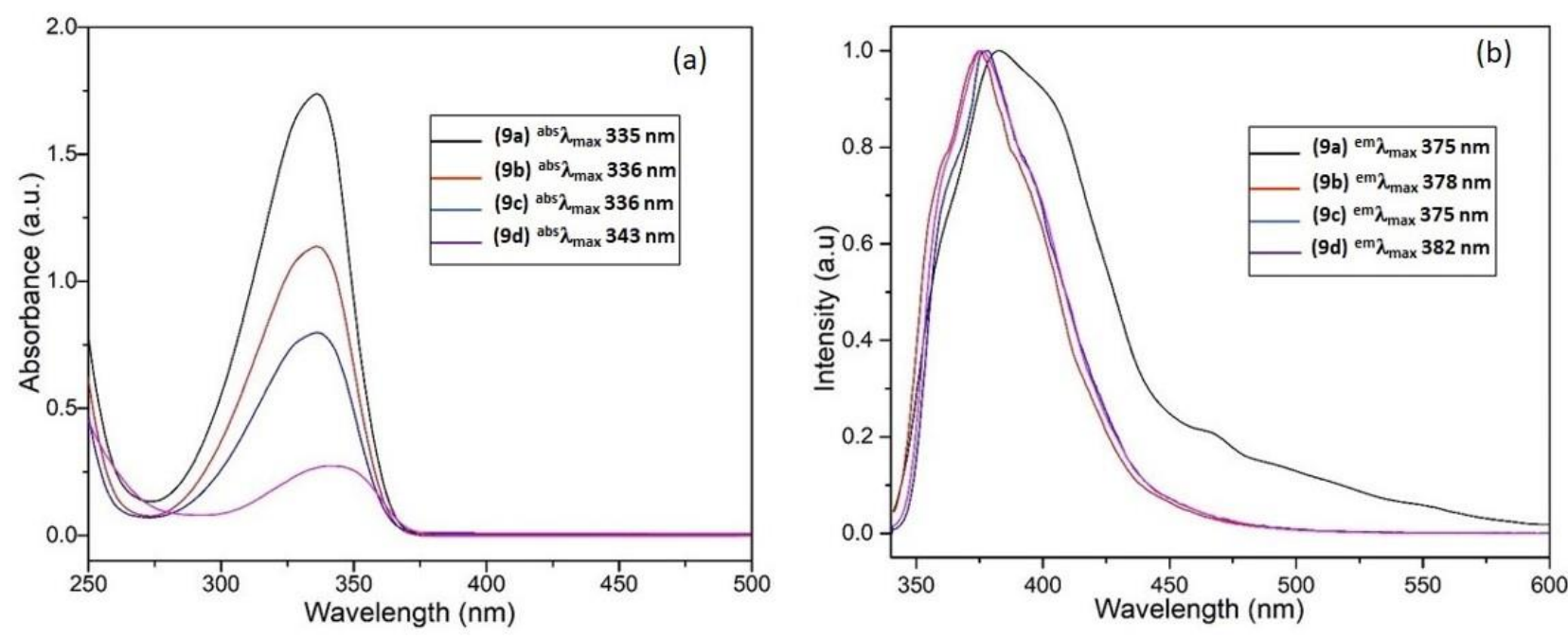

Figure 4. (a) UV-visible spectra of $\mathbf{9 a - d}$ in acetonitrile solution; (b) normalized fluorescence spectra of $\mathbf{9 a - d}$ at a concentration of $1 \times 10^{-6} \mathrm{M}$ in acetonitrile solution.

\subsection{Fluorescence Emission}

The excited state behavior of naphthalimide analogs $\mathbf{9 a}-\mathbf{d}$ was evaluated by recording their fluorescent emission spectra in acetonitrile solutions ( ${ }^{\mathrm{em}} \lambda_{\max }=375-382 \mathrm{~nm}$ ). As shown in Figure $4 \mathrm{~b}$, all the naphthalimide analogs showed a similar range of emission, which is slightly red-shifted to ${ }^{\mathrm{em}} \lambda_{\max }=382 \mathrm{~nm}$ in the case of compound $9 \mathrm{~d}$. The spectrum of this compound also exhibits a shoulder at ${ }^{\mathrm{em}} \lambda_{\max }=411 \mathrm{~nm}$, which is due to the presence of the electron-withdrawing $\mathrm{NO}_{2}$ group in the 5-position of the naphthalimide ring, reducing the $\pi$-electron conjugation between the chalcone spacer and the naphthalimide aromatic ring. Table 3 summarizes the photophysical properties of naphthalimides $\mathbf{9 a - d}$. In addition, Figure 5 displays the fluorescence emissions of these compounds upon exposure to UV light.

Table 3. Photophysical properties of naphthalimide analogs $9 \mathbf{a}-\mathbf{d}$ in acetonitrile at a concentration of $1 \times 10^{-6} \mathrm{M}$.

\begin{tabular}{cccc}
\hline S.No. & Fluorophore & ${ }^{\mathrm{abs}} \boldsymbol{\lambda}_{\max }(\mathbf{n m})$ & ${ }^{\mathrm{em}} \boldsymbol{\lambda}_{\max }(\mathbf{n m})$ \\
\hline 1. & $\mathbf{9 a}$ & 335 & 375 \\
2. & $\mathbf{9 b}$ & 336 & 378 \\
3. & $\mathbf{9 c}$ & 336 & 375 \\
4. & $\mathbf{9 d}$ & 343 & 382 \\
\hline
\end{tabular}




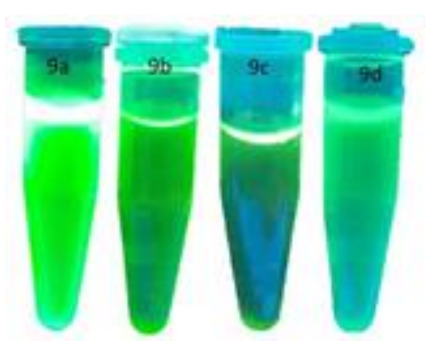

Figure 5. Blue light emission of 9a-d under 365 nm UV irradiation.

As reported by Xiao et al., the fluorescence emission of MEBN was sensitive to solvent polarity, and the corresponding bands were gradually shifted to lower energies with increasing solvent polarity [29]. The effect of the polarity of the medium on the photoluminescent emission maximum was more pronounced than on the absorption maximum. The long wavelength of fluorescence emission observed in more polar solvents is due to an intramolecular charge-transfer transition. In this context, Saito et al. [30] designed three fluorescent probes integrated in a molecular system, in which the introduction of amines as receptors enabled the photo-induced electron transfer process.

\subsection{Antimicrobial Activity}

\subsubsection{In Vitro Antibacterial Activities}

The agar well diffusion method was used to determine the antibacterial activities of the synthesized imide compounds $\mathbf{5 a - c}$ and $\mathbf{9 a}-\mathbf{d}$. The bacterial strains used in these studies were S. aureus MTCC 25923 and E. coli MTCC 25922, and tetracycline was used as a positive control. Compound $\mathbf{9 b}$ was effective in controlling both pathogens with a large zone of inhibition at a concentration of 50,75, and $100 \mu \mathrm{g} / \mathrm{mL}$. However, interestingly, the zone of inhibition was almost the same as that of the positive control at the higher concentration $(100 \mu \mathrm{g} / \mathrm{mL})$. Moreover, $\mathbf{5 c}, \mathbf{9 c}$, and $\mathbf{5 b}$ showed antibacterial effects for both strains, with zones of inhibitions of $10-23 \mathrm{~mm}, 9-18 \mathrm{~mm}$, and 8-18 mm, respectively (Table 2).

\subsubsection{In Vitro Antifungal Activity}

The antifungal activity of compounds $\mathbf{5 a}-\mathbf{c}$ and $\mathbf{9 a}-\mathbf{d}$ was evaluated against two fungal strains, viz., A. niger MTCC 227 and C. albicans MTCC 282, at various concentrations $(\mu \mathrm{g} / \mathrm{mL})$ using the disk diffusion technique and the inhibition data are presented in Table 4. Compound $9 \mathbf{b}$ could effectively control both fungal pathogens with zone of inhibition values of $11-28 \mathrm{~mm}$ at concentrations of $50-100 \mu \mathrm{g} / \mathrm{mL}$. The polymer $5 \mathrm{c}$ showed a moderate zone of inhibition between 11 and $26 \mathrm{~mm}$, and $5 \mathbf{b}$ and $9 \mathbf{c}$ exhibited efficient inhibition ranges compared with carbendazim as a positive control. Figure 6 displays a representative graph summarizing these results and the zone of inhibition of high-efficacy polymer $\mathbf{9 b}$ is presented in Figure 7. 
Table 4. (a) Zone of inhibition of compounds 5a-c and 9a-d against bacterial pathogens. (b) Zone of inhibition of compounds $5 \mathbf{a}-\mathbf{c}$ and $\mathbf{9 a}-\mathbf{d}$ against fungal pathogens.

(a)

\begin{tabular}{|c|c|c|c|c|c|c|}
\hline \multirow{3}{*}{$\begin{array}{c}\text { Compounds and Positive } \\
\text { Control }\end{array}$} & \multicolumn{6}{|c|}{ Zone of Inhibition $(\mathrm{mm}) /$ Concentrations $(\mu \mathrm{g} / \mathrm{mL})$} \\
\hline & \multicolumn{3}{|c|}{ E. coli } & \multicolumn{3}{|c|}{ S. aureus } \\
\hline & 50 & 75 & 100 & 50 & 75 & 100 \\
\hline $5 a$ & $8.00 \pm 0.10$ & $10.00 \pm 0.14$ & $10.00 \pm 0.25$ & $6.00 \pm 0.05$ & $9.00 \pm 0.35$ & $10.00 \pm 0.75$ \\
\hline $5 \mathbf{b}$ & $11.00 \pm 0.15$ & $13.00 \pm 0.30$ & $16.00 \pm 0.15$ & $8.00 \pm 0.10$ & $9.00 \pm 0.22$ & $18.00 \pm 1.10$ \\
\hline $5 c$ & $10.00 \pm 0.20$ & $15.00 \pm 0.18$ & $18.00 \pm 0.09$ & $11.00 \pm 0.80$ & $16.00 \pm 0.17$ & $23.00 \pm 0.90$ \\
\hline 9a & $10.00 \pm 0.18$ & $12.00 \pm 0.09$ & $19.00 \pm 0.45$ & $9.00 \pm 0.20$ & $13.00 \pm 0.12$ & $18.00 \pm 1.00$ \\
\hline $9 b$ & $16.00 \pm 0.05$ & $20.00 \pm 0.40$ & $24.00 \pm 0.70$ & $14.00 \pm 0.30$ & $17.00 \pm 0.25$ & $22.00 \pm 1.20$ \\
\hline $9 c$ & $11.00 \pm 1.05$ & $14.00 \pm 0.28$ & $18.00 \pm 0.90$ & $9.00 \pm 0.05$ & $11.00 \pm 0.20$ & $17.00 \pm 0.65$ \\
\hline $9 d$ & NZI @ & $7.00 \pm 0.65$ & $9.00 \pm 0.15$ & NZI & $6.00 \pm 0.08$ & $7.00 \pm 0.15$ \\
\hline $\mathrm{TE}^{*}$ & & $26.00 \pm 1.00$ & & & $25.00 \pm 0.75$ & \\
\hline
\end{tabular}

(b)

\begin{tabular}{|c|c|c|c|c|c|c|}
\hline \multirow{3}{*}{$\begin{array}{c}\text { Compounds and Positive } \\
\text { Control }\end{array}$} & \multicolumn{6}{|c|}{ Zone of Inhibition $(\mathrm{mm}) /$ Concentrations $(\mu \mathrm{g} / \mathrm{mL})$} \\
\hline & \multicolumn{3}{|c|}{ C. albicans } & \multicolumn{3}{|c|}{ A. niger } \\
\hline & 50 & 75 & 100 & 50 & 75 & 100 \\
\hline $5 \mathbf{a}$ & $6.00 \pm 0.08$ & $9.00 \pm 0.08$ & $12.00 \pm 0.40$ & $9.00 \pm 0.10$ & $13.00 \pm 0.15$ & $18.00 \pm 0.75$ \\
\hline $5 b$ & $9.00 \pm 0.15$ & $11.00 \pm 0.80$ & $12.00 \pm 0.20$ & $7.00 \pm 0.10$ & $14.00 \pm 0.60$ & $20.00 \pm 0.80$ \\
\hline $5 c$ & $12.00 \pm 0.16$ & $16.00 \pm 1.00$ & $22.00 \pm 0.35$ & $11.00 \pm 0.10$ & $18.00 \pm 0.75$ & $24.00 \pm 0.65$ \\
\hline $9 a$ & NZI @ & $7.00 \pm 0.05$ & $9.00 \pm 0.45$ & $10.00 \pm 0.10$ & $16.00 \pm 0.95$ & $18.00 \pm 0.50$ \\
\hline $9 b$ & $11.00 \pm 0.55$ & $19.00 \pm 0.95$ & $21.00 \pm 0.55$ & $12.00 \pm 0.10$ & $19.00 \pm 0.45$ & $25.00 \pm 0.35$ \\
\hline $9 c$ & $8.00 \pm 0.07$ & $8.00 \pm 0.08$ & $10.00 \pm 0.60$ & $10.00 \pm 0.10$ & $12.00 \pm 0.15$ & $13.00 \pm 0.25$ \\
\hline $9 d$ & NZI & $7.00 \pm 0.04$ & $9.00 \pm 0.15$ & $8.00 \pm 0.10$ & $11.00 \pm 0.20$ & $11.00 \pm 0.30$ \\
\hline $\mathrm{CA}^{\$}$ & & $24.00 \pm 1.25$ & & & $25.00 \pm 1.15$ & \\
\hline
\end{tabular}

Note: TE ${ }^{*}$ t tetracycline; NZI ${ }^{\circledR}:$ no zone of inhibition. CA $^{\$}$ : carbendazim; NZI ${ }^{\circledR}:$ no zone of inhibition.
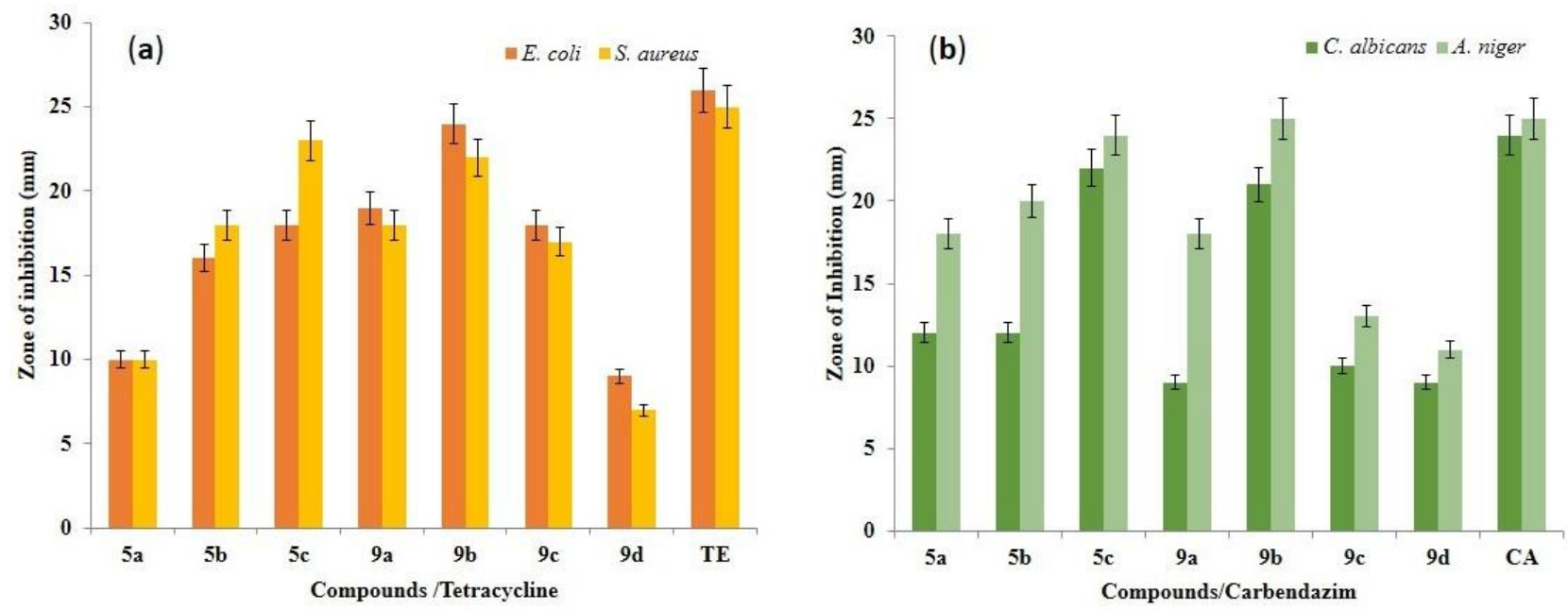

Figure 6. Antimicrobial efficiency of compounds 5a-c and 9a-d. (a) Zone of inhibition of tested bacteria, i.e., E. coli MTCC 25922 and S. aureus MTCC 25923. (b) Zone of inhibition of tested fungi, i.e., C. albicans MTCC 282 and A. niger MTCC 227. Results are expressed as mean $\pm \mathrm{SD}$ for $n=3$. Bars with the same letter are not significantly different at $p>0.05$. 


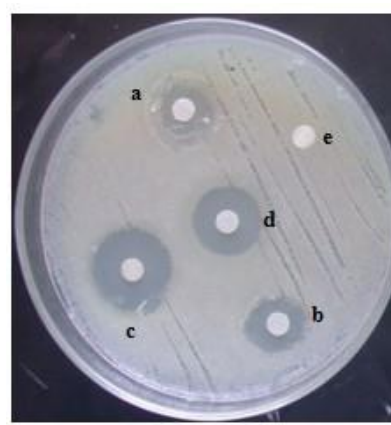

Escherichia coli

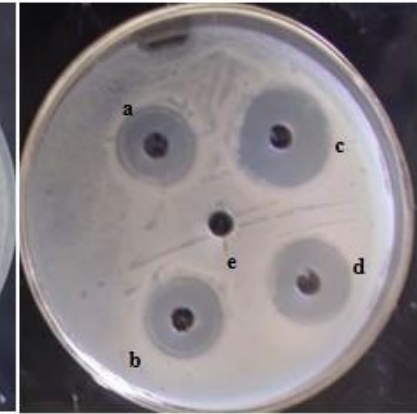

Staphylococcus aureus

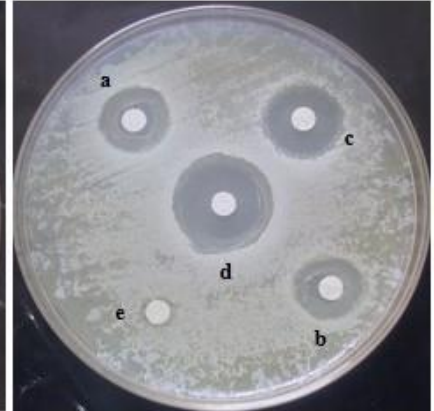

Candida albicans

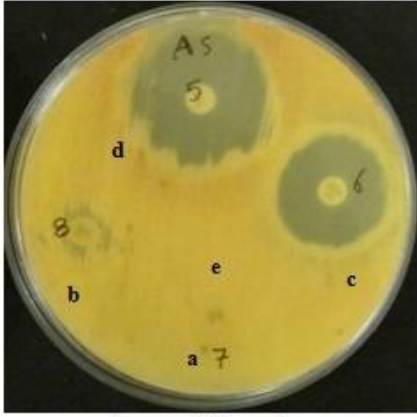

Aspergillus niger

Figure 7. Antimicrobial activity of compound $\mathbf{9 b}$ against common bacterial pathogens. a: $50 \mu \mathrm{L}, \mathrm{b}: 75 \mu \mathrm{L}, \mathrm{c}: 100 \mu \mathrm{L}, \mathrm{d}$ : positive control, e: negative control.

\section{Conclusions}

The synthesis of new multiblock chalcone conjugate phthalimide and naphthalimide functionalized copolymers with a topologically novel architecture synthesis using nucleophilic substitution and polycondensation methodology have been successfully explored. We have synthesized phthalimide- and naphthalimide-containing novolac analogs conjugated with a chalcone spacer via sequential nucleophilic substitution and condensation

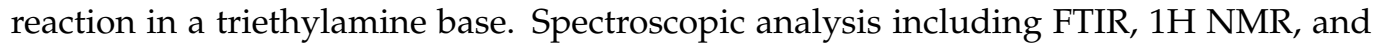
13C NMR spectroscopy confirms the structures of the synthesized novolacs. The synthesized multi-block novolacs are photoactive; notably, 1,8-naphthalimide pendant organic functional group novolacs showed interesting optical activity compared to the other phthalimide pendent functionalized novolacs. All the 1,8-naphthalimide derivatives showed UV absorption and emission.

Employing gel permeation chromatography (GPC), the number- and weight-average molecular weights of the novolac polymers were determined. On examining the solubility of synthesized polymers in various organic solvents including $\mathrm{CHCl}_{3}, \mathrm{CH}_{3} \mathrm{CN}, \mathrm{THF}, \mathrm{H}_{2} \mathrm{O}$, $\mathrm{CH}_{3} \mathrm{OH}, \mathrm{DMSO}$, DMF, etc., these novolac polymers were insoluble in methanol and water. Photophysical properties and microbial activities of the synthesized novolac polymers were evaluated. The investigation of the antimicrobial activities of these polymers reveals significant antimicrobial activity against the pathogens E. coli, S. aureus, C. albicans, and $A$. niger. The in vitro antibacterial activities against $E$. coli and $S$. aureus and the in vitro antifungal activities against $C$. albicans and $A$. niger were evaluated for the novolacs using the MIC method. The antimicrobial efficacy of all the synthesized novolacs showed interesting results for all the tested pathogens. The MIC values of all synthesized compounds are found to be effective compared to the standard drugs tetracycline and carbendazim. Particularly, compounds $9 b$ and $5 c$ showed their effective inhibition of both Gram-positive and Gram-negative pathogens. The present study strongly supports that the synthesized organic multi-block functionalized novolacs are optically active materials for materials science applications and also act as suitable material for a wide range of antimicrobial applications in health-associated sectors.

Supplementary Materials: The following are available online at https:/ /www.mdpi.com/article/10 $.3390 /$ polym13111859/s1, S1.

Author Contributions: Conceptualization, P.D. and G.P.; methodology, G.P.; validation, P.A.V., C.U. and M.R.; formal analysis, C.U.; investigation, P.D.; data curation, G.P.; writing original draft preparation, P.D.; writing-review and editing, G.P. and P.A.V.; supervision, C.U. and M.R.; funding acquisition, G.P. All authors have read and agreed to the published version of the manuscript.

Funding: The authors express their appreciation to the Deanship of Scientific Research at King Saud University for funding this work through research group no. RG-1440-111.

Institutional Review Board Statement: Not applicable. 
Informed Consent Statement: Not applicable.

Data Availability Statement: The data presented in this study are available on request from the corresponding author.

Acknowledgments: The authors express their appreciation to the Deanship of Scientific Research at King Saud University for funding this work through research group no. RG-1440-111. The authors thank the Deanship of Scientific Research and RSSU at King Saud University for their technical support. We would like to express their gratitude and thanks to Masilmani Jaganmohan, Faculty of Chemistry, Indian Institute Madras, India, for providing the NMR data.

Conflicts of Interest: The authors declare no conflict of interest.

\section{References}

1. Wang, L.; Fujii, M.; Yamaji, M.; Okamoto, H. Fluorescence behaviour of 2-, 3- and 4-amino-1,8-naphthalimides: Effects of the substitution positions of the amino functionality on the photophysical properties. Photochem. Photobiol. Sci. 2018, 17, 1319-1328. [CrossRef] [PubMed]

2. Orita, R.; Franckeviclus, M.; Vysniauskas, A.; Gulbinas, V.; Sugiyama, H.; Uekusa, H.; KanosueKishige, R.; Ando, S. Enhanced fluorescence of phthalimide compounds induced by the incorporation of electron-donating alicyclic amino groups. Phys. Chem. Chem. Phys. 2018, 20, 16033-16044. [CrossRef] [PubMed]

3. Yoon, U.C. and Mariano, P.S. The Synthetic Potential of Phthalimide SET Photochemistry. Acc. Chem. Res. 2001, 34, 523-533. [CrossRef] [PubMed]

4. Bansode, T.N.; Shelke, J.V.; Dongre, V.G. Synthesis and antimicrobial activity of some new N-acyl substituted phenothiazines. Eur. J. Med. Chem. 2009, 44, 5094-5098. [CrossRef]

5. Kamal, A.; Bolla, N.R.; Srikanth, P.S.; Srivastava, A.K. Naphthalimide derivatives with therapeutic characteristics: A patent review. Expert Opin. Ther. Pat. 2013, 23, 299-317. [CrossRef]

6. Rajasekaran, S.; Rao, G.K.; Pai, S.; Ranjan, A. Design, Synthesis, Antibacterial and invitro Antioxidant activity of substituted 2HBenzopyran-2-one derivatives. Int. J. Chem. Tech. Res. 2011, 3, 555-559.

7. Santos, J.L.; Yamasaki, P.R.; Chin, C.M.; Takashi, C.H.; Pavan, F.R.; Leite, C.Q. Synthesis and in vitro anti Mycobacterium tuberculosis activity of a series of phthalimide derivatives. Bioorganic Med. Chem. 2009, 17, 3795-3799. [CrossRef] [PubMed]

8. Srinivasan, R.; Kumar, K.R.; Kumar, P.P. Synthesis and Antimicrobial Activity of some New $\alpha$ N-Phthilimido Amino Acids Analogues. Int. J. Chem. Tech. Res. 2010, 2, 895-898.

9. Horvat, M.; Uzelac, L.; Marjanovic, M.; Cindro, N.; Frankovic, O.; Mlinaric-Majerski, K.; Kralj, M.; Basaric, N. Evaluation of antiproliferative effect of N-(alkyladamantyl)phthalimides in vitro. Chem. Biol. Drug. Des. 2012, 79, 497-506. [CrossRef] [PubMed]

10. Singh, A.K.; Rajendran, V.; Pant, A.; Ghosh, P.C.; Singh, N.; Latha, N.; Rathi, B. Design, synthesis and biological evaluation of functionalized phthalimides: A new class of antimalarials and inhibitors of falcipain-2, a major hemoglobinase of malaria parasite. Bioorganic Med. Chem. 2015, 23, 1817-1827. [CrossRef]

11. Iwai, Y.; Takahashi, H.; Hatakeyama, D.; Motoshima, D.; Ishikawa, M.; Sugita, K.; Kuzuhara, T. Anti-influenza activity of phenethylphenylphthalimide analogs derived from thalidomide. Bioorganic Medic. Chem. 2010, 18, 5379-5390. [CrossRef]

12. Vivekanand, P.A.; Wang, M.L.; Hsieh, Y.M. Sonolytic and Silent Polymerization of Methacrlyic Acid ButylEster Catalyzed by a New Onium Salt with bis-Active Sites in a Biphasic System-A Comparative Investigation. Molecules 2013, 18, $2419-2437$. [CrossRef] [PubMed]

13. Coêlho, L.C.D.; Cardoso, M.V.; Moreira, O.d.D.R.M.; Gomes, P.A.T.; Cavalcanti, M.d.S.M.T.; Oliveira, A.R.; Leite, A.C.L. Novel phthalimide derivatives with TNF- $\alpha$ and IL-1 $\beta$ expression inhibitory and apoptotic inducing properties. Med. Chem. Commun. 2016, 5, 758-765. [CrossRef]

14. Pan, L.; Li, X.; Gong, C.; Jin, H.; Qin, B. Synthesis of N-substituted phthalimides and their antifungal activity against Alternaria solani and Botrytis cinerea. Micro Pathog. 2016, 95, 186-192. [CrossRef] [PubMed]

15. Chanh, T.C.; Lewis, D.E.; Judy, M.M.; Sogandares-Bernal, F.; Michalek, G.R.; Utecht, R.E.; Matthews, J.L. Inhibition of retrovirusinduced syncytium formation by photoproducts of a brominated 1,8-naphthalimide compound. Antivir. Res. 1994, 25, 133-146. [CrossRef]

16. Ghosh, P.; Singha Roy, S.; Basu, A.; Bhattacharjee, A.; Bhattacharya, S. Sensitization of cis-platin therapy by a naphthalimide based organoselenium compound through modulation of antioxidant enzymes and p53 mediated apoptosis. Free Radic. Res. 2015, 49, 453-471. [CrossRef]

17. Chen, Z.; Liang, X.; Zhang, H.; Xie, H.; Liu, J.; Xu, Y.; Qian, X. A New Class of Naphthalimide-Based Antitumor Agents That Inhibit Topoisomerase II and Induce Lysosomal Membrane Permeabilization and Apoptosis. J. Med. Chem. 2010, 53, 2589-2600. [CrossRef]

18. Staneva, D.; Vasileva-Tonkova, E.; Grabchev, I. A New Bioactive Complex between Zn(II) and a Fluorescent Symmetrical Benzanthrone Tripod for an Antibacterial Textile. J. Photochem. Photobiol. A Chem. 2019, 375, 24-29. [CrossRef]

19. Al-Azzawi, A.M.; Faiq, E. Synthesis and Modification of New Phenolic Resins Bearing Pendant 1,8-Naphthalimides. Int. J. Sci. Res. 2017, 6, 1498-1504. 
20. Zhang, X.; Zhang, J.; Lu, H.; Wu, J.; Li, G.; Li, C.; Bo, Z. A 1,8-naphthalimide based small molecular acceptor for polymer solar cells with high open circuit voltage. J. Mater. Chem. C 2015, 3, 6979-6985. [CrossRef]

21. Grabchev, I.; Petkov, C.; Bojinov, V. 1,8-Naphthalimides as Blue Emitting Fluorophores for Polymer Materials. Macromol. Mater. Eng. 2002, 287, 904-908. [CrossRef]

22. Christopherson, C.J.; Mayder, D.M.; Poisson, J.; Paisley, N.R.; Tonge, C.M.; Hudson, Z.M. 1,8-Naphthalimide-Based Polymers Exhibiting Deep-Red Thermally Activated Delayed Fluorescence and Their Application in Ratiometric Temperature Sensing. ACS Appl. Mater. Interfaces 2020, 12, 20000-20011. [CrossRef] [PubMed]

23. Chen, S.; Jia, Y.; Zou, G.-Y.; Yu, Y.-L.; Wang, J.-H. A ratiometric fluorescent nanoprobe based on naphthalimide derivativefunctionalized carbon dots for imaging lysosomal formaldehyde in HeLa cells. Nanoscale 2019, 11, 6377-6383. [CrossRef] [PubMed]

24. Abdel-Aziz, A.A.-M.; El-Azab, A.S.; El-Enin, M.A.A.; Almehizia, A.A.; Supuran, C.T.; Nocentini. A. Synthesis of novel isoindoline1,3-dione-based oximes and benzenesulfonamide hydrazones as selective inhibitors of the tumor-associated carbonic anhydrase IX. Bioorganic Chem. 2018, 80, 706-713. [CrossRef] [PubMed]

25. CLSI. Performance Standards for Antimicrobial Susceptibility Testing, 30th ed.; CLSI Supplement M100; Clinical and Laboratory Standards Institute: Wayne, PA, USA, 2020.

26. Cao, Y.; Gao, M.; Chen, C.; Fan, A.; Zhang, J.; Kong, D.; Wang, Z.; Peer, D.; Zhao, Y. Triggered-release polymeric conjugate micelles for on-demand intracellular drug delivery. Nanotechnology 2015, 26, 115101. [CrossRef] [PubMed]

27. Al-Azzawi, A.M.; Yaseen, H. Synthesis and curing of new phenolic resins containing pendant tetrachlorophthalimides. Iraqi J. Sci. 2016, 57, 1345-1356.

28. Bojinov, V.B.; Panova, I.P.; Simeonov, D.B.; Georgiev, N.I. Synthesis and sensor activity of photostable blue emitting 1,8naphthalimides containing s-triazine UV absorber and HALS fragments. J. Photochem. Photobiol. A Chem. 2010, 210, 89-99. [CrossRef]

29. Xiao, H.; Chen, M.; Shi, G.; Wang, L.; Yin, H.; Mei, C. A novel fluorescent molecule based on 1,8-naphthalimide: Synthesis, spectral properties, and application in cell imaging. Res. Chem. Intermed. 2010, 36, 1021-1026. [CrossRef]

30. Saito, G.; Velluto, D.; Resmini, M.R. Synthesis of 1,8-naphthalimide-based probes with fluorescent switch triggered by flufenamic acid. Soc. Open. Sci. 2018, 5, 172137. [CrossRef] 